\title{
El órgano en el oratorio de San Felipe Neri de Sevilla
}

\author{
The organ in the St. Philip Neri'Oratory \\ of Seville
}

\author{
Jorge Alberto Jordán Fernández \\ Doctor en Historia \\ jorgeajordan@gmail.com \\ ID ORCID 0000-0003-3197-2171
}

\begin{abstract}
Resumen: En este artículo nos aproximamos al conocimiento de la historia del órgano en la Congregación del Oratorio de San Felipe Neri de Sevilla desde el siglo XVII al XX, confrontando las noticias ya conocidas con nuevas aportaciones documentales.
\end{abstract}

Palabras clave: Sevilla, oratorio de San Felipe Neri, órganos, siglos XVII-XX.

\begin{abstract}
In this paper we approach to the knowledge of the history from the organ in the St. Philip Neri's Oratory of Seville, overthe 17th century to the 20th century, to face up well-known news with news documentary contributions.
\end{abstract}

Keywords: Seville, St. Philip Neri's Oratory, organs, 17th-20th centuries.

\section{INTRODUCCIÓN}

La historia de la congregación del oratorio de San Felipe Neri de Sevilla resulta bastante bien conocida en nuestros días, así como también el rico patrimonio artístico que poseyó y aún posee, gracias especialmente al trabajo de los profesores Martín Riego y Roda Peña y a los de otros investigadores. ${ }^{1}$ Los hijos de san Felipe Neri llegaron

1 Cf. Manuel Martín Riego y José Roda Peña, El Oratorio de San Felipe Neri de Sevilla. Historia y patrimonio artístico. Córdoba: Obra Social y Cultural CAJASUR, 2004. Sin ánimo de ser exhaustivos, pueden consultarse también Pedro Fernández De La Cuesta, La Congregación del Oratorio San Felipe Neri de Sevilla. Gloria y glosa de tres siglos de historia, XVIII al XX. Sevilla: Guadalquivir ediciones, 1999: Manuel Martín Riego, "El Oratorio de San Felipe Neri de Sevilla (16981893)”. Isidorianum, no 7 (1998) 483-545; ID."Exclaustración y restauración de la 
a la ciudad del Betis a finales del siglo XVII con la intención de fundar en ella un oratorio, ${ }^{2}$ nombre con el que eran conocidas popularmente las casas de este peculiar instituto religioso, fundado por el florentino Felipe Neri en el siglo XVI. Concretamente, el 8 de febrero de 1698 los oratorianos Francisco Navascués Pérez y Félix de Rivera Arroyal, procedentes de la congregación filipense de Granada, llegaron a Sevilla para llevar a cabo esta nueva fundación, que pronto recibió los parabienes del prelado diocesano, a la sazón el arzobispo Jaime Palafox y Cardona (1684-1701) y del cabildo secular; la primera instalación tuvo lugar en la calle Costales, a la collación de Santa Catalina, cuya iglesia fue bendecida en noviembre de 1698 por Francisco Lelio Levanto, arcediano de Niebla, en nombre del arzobispo; la erección canónica del oratorio sevillano tuvo lugar el 27 de dichos mes y año. ${ }^{3}$ Desde entonces y hasta el presente, los filipenses han participado de la vida de la ciudad, especialmente en su faceta espiritual, presencia que sólo ha sido interrumpida momentáneamente en varias ocasiones durante el turbulento siglo XIX con motivo de las diversas exclaustraciones de los religiosos que se decretaron entonces.

Por otra parte, la música ha sido un arte especialmente cultivada por los hijos de San Felipe desde sus orígenes, tanto que sus prácticas religiosas han terminado por dar nombre a cierta composición musical conocida como oratorio, un canto en forma dialogal que solía interpretarse en sus celebraciones litúrgicas. ${ }^{4}$ Testigo directo de este quehacer musical de los filipenses sevillanos fue el nada sospechoso

Congregación del Oratorio de San Felipe Neri de Sevilla (1836-1876). Memoria Ecclesiae, $n^{\circ}$ XXIII (2003), 231-258; ID. “El Oratorio de San Felipe Neri de Sevilla (1698-2002)", en Enrique Barrero GonzÁlez-Ismael Martínez Carretero (coords.), Órdenes y congregaciones religiosas en Sevilla. Sevilla: Ateneo y Fundación CAJASOL, 2008, 411-447; y Matilde FERnÁndez Rojas, Patrimonio artístico de los conventos masculinos desamortizados en Sevilla durante el siglo XIX: trinitarios, (...) y Filipenses. Sevilla: Diputación Provincial, 2009, 502-532.

2 Justino Matute reseña la fundación de un oratorio de San Felipe Neri en Sevilla, extinguido al parecer en 1636, pero la noticia es ciertamente confusa; cfr. Justino Matute Y Gavira, Noticias relativas a la historia de Sevilla que no constan en sus Anales... Sevilla: Imprenta de E. Rasco, 1886, edición facsímil en Mairena del Aljarafe (Sevilla): Extramuros ediciones, 2011, 118-119.

3 Cf. Martín Riego, “El Oratorio”, 411-417.

4 Una visión panorámica acerca de esta cuestión puede verse en M ${ }^{\mathrm{a}}$ Teresa FERRER Ballester y Rosa Sanz Hermida, "«Motete o stropha spiritual en forma de diálogo»: los oratorios de la Congregación de San Felipe Neri en el inicio de la Guerra de Sucesión (1702-1706)", en Rosa Isusi-FagOAGa y Francesc VilLanUEva 
Blanco White, quien lo recordaba así en su Autobiografía: "Por otro lado, la iglesia de San Felipe Neri tenía para mí otra gran atracción: en ella se escuchaba música con tanta frecuencia que con razón San Felipe Neri podía ser considerada como la Ópera religiosa de Sevilla"; y a continuación detallaba pormenorizadamente la experiencia musical vivida con los filipenses sevillanos: ${ }^{5}$

Los buenos padres del Oratorio habían ideado un ingenioso plan para que la música no les costara dinero. Para ello cultivaban la amistad de los mejores músicos profesionales de la ciudad y recompensaban sus servicios dándoles, por un lado, ayuda espiritual, y por otro, prestigio mundano. Como también había en nuestra ciudad buen número de aficionados, cuya cooperación gratuita pudiera dar más fuerza a la orquesta, los padres habían preparado un lugar en la iglesia, oculto por una celosía, donde los caballeros aficionados podían unirse a la orquesta sin ser vistos del público. La buena sociedad sevillana, en vez de considerar degradante este servicio, lo consideraba al contrario, como un excelente acto de devoción. Como yo había conseguido tocar el violín aceptablemente, los padres filipenses consideraban mis servicios muy valiosos y a mí, por mi parte, me llenaba de satisfacción la oportunidad de unirme a una gran orquesta. De esta manera, contaba con una hora de práctica del violín todos los domingos por la tarde y en las tres o cuatro fiestas principales que se celebraban todos los años y en las que la música sonaba casi sin parar desde las primeras horas de la mañana hasta la puesta de sol, tocaba el violín hasta que mis dedos estaban a punto de sangrar.

Esto sucedía en los últimos años del siglo XVIII, cuando aún los oratorianos tenían su iglesia en la collación de Santa Catalina y estaban viviendo sus mejores tiempos en la ciudad, pues tras la expulsión de los jesuitas se convirtieron en uno de los principales referentes de la religiosidad local.

Y si de música sacra se habla, no puede obviarse la presencia imprescindible del órgano como instrumento musical por excelencia en los templos, también en los filipenses; no han sido, sin embargo, estas piezas objeto de atención de la historiografía reciente sobre el oratorio hispalense, y a intentar paliar dicha laguna van dirigidas las páginas que siguen, reuniendo en ellas cuantas noticias hemos

SERRANO (eds.) La música de la corona d' Aragó: investigació, transferencia y educació. Valencia: Universidad, 2020, 121-139.

5 José Blanco White, Autobiografía. Edición y notas de Antonio Garnica. Sevilla: Universidad, 1988, 54-55. 
podido encontrar acerca del devenir de este instrumento musical entre los filipenses sevillanos, instrumento tan insigne $\mathrm{y}$, al mismo tiempo, tan preterido.

\section{EL ÓRGANO DE LA IGLESIA DE SAN FELIPE NERI}

A diferencia de lo que ocurrió con la casa madre de la que procedía, el oratorio de Granada, ${ }^{6}$ los filipenses sevillanos contaron desde bien pronto con un órgano propio en su iglesia, edificada de nueva planta entre agosto de 1709 y julio de 1711, en que fue bendecido el nuevo templo por el obispo Pedro Levanto, auxiliar de Sevilla (1703-1729), siendo prepósito del oratorio el P. Juan Antonio Sedeño (1708-1714). ${ }^{7}$ De este primer órgano sólo sabemos lo que costó, 2.130 reales, ${ }^{8}$ por lo que o bien debió tratarse de un instrumento de modestas proporciones o bien fue adquirido de lance. Sea de ello lo que fuere, todo parece indicar que este primer órgano de los filipenses sevillanos fue sustituido por uno nuevo durante la prepositura del P. Teodomiro Díaz de la Vega (1792-1804); concretando más, parece que el nuevo órgano ya estaba realizado en febrero de $1796:^{9}$

Los congregantes quisieron expresar su agradecimiento al P. Díaz de la Vega en la Congregación General del 5 de febrero de 1796. El acta enumera las obras realizadas por Teodomiro. Había ampliado la iglesia de la casa, formado las tribunas, órgano, tabernáculo de San Felipe (...). En la obra de la iglesia y de la sacristía había gastado 220.000 reales y en la capilla mayor y presbiterio 375.000 reales.

En cuanto a su artífice, José $\mathrm{M}^{\mathrm{a}}$ Tassara afirma, sin citar la fuente, que "fue uno de los mejores construidos por el famoso maestro Calvete, [y] existe hoy en la ya citada iglesia parroquial de Nuestra

6 "En cuanto atañe al órgano, la iglesia nueva no contó con uno propio de gran envergadura hasta que el 1 de julio de 1747 se compró a las capuchinas el que estas venían prestando a los oratorianos para las funciones". José Antonio DíAZ Gómez, El Oratorio de San Felipe Neri de Granada. Historia y patrimonio de una fundación perseguida. Granada: editorial Comares, 2021, 269.

7 Sobre este prepósito hay una breve reseña en Justino MATUTEY GAVIRIA, Aparato para escribir la historia de Triana y de su iglesia parroquial. Sevilla: Imprenta de D. Manuel Carrera y compañía, 1818, edición facsímil en Sevilla: Colegio Oficial de Aparejadores y Arquitectos Técnicos de Sevilla, 1988, 180-181.

8 Cf. Martín Riego y Roda PeÑa, El Oratorio, 62.

9 Ibídem, p. 131. La cursiva es nuestra. 
Señora de la $\mathrm{O}$, Triana",i10Ayarra, por su parte, más cauto, parece apostar por la intervención de Calvete en este órgano tan sólo como reparador o reformador al decir que "conservamos todavía otros tres instrumentos en los que el Maestro Calvete, si no los hizo nuevos, realizó importantes reparaciones o reformas", y concretando más aún:"es verdad que [Calvete] respetará las cajas o fachadas antiguas, cuando su trabajo se reduzca a una nueva reparación o reforma, como ocurre -por ejemplo- en el de la parroquia de Nuestra Señora de la O de Triana"; ${ }^{11}$ por los datos que conocemos acerca de la biografía del maestro Antonio Otín Calvete, y teniendo en cuenta que el órgano nuevo de los filipenses estaba ya instado en febrero de 1796, nos inclinamos a considerar como más acertada la apreciación de Ayarra. ${ }^{12}$

Un testigo de la época, el oratoriano Cayetano Fernández, nos describía someramente el instrumento en su ubicación original: ${ }^{13}$

Bajo el siguiente arco [segundo del lado del Evangelio] no había capilla, por ser el que daba paso a la galería (...) en la tribuna que descansaba sobre dicho arco, estaba montado el órgano que, sin duda alguna, era el mejor de Sevilla, aparte los dos incomparables de la Catedral. Tenía el nuestro escogidísimos registros, suaves y fuertes, dulces y estrepitosos, comunes y bastante raros, con sus correspondientes contras, por todos en número de 20. La caja era de pino con sobrepuestos de talla, pintada y dorada. Los que lo oyeron no podrán olvidar nunca aquellas melodiosas meditaciones,

10 José Ma TASSARa y González, Apuntes para la historia de la Revolución de Septiembre del año 1868, en la ciudad de Sevilla. Sevilla: Gironés, 1919, 88; citamos por la edición facsímil de Sevilla, 2000.

11 José Enrique Ayarra, El órgano en Sevilla y su provincia. Sevilla: Obra Cultural de la Caja de Ahorros San Fernando, 1978, 133 y 141; acerca del mueble de este instrumento dice que es "barroco, pintado en verdes y dorados" y que"se mantiene fiel a la fachada tradicional sevillana del siglo XVIII" (141).

12 Antonio Otín Calvete nació en Sevilla en 1767; hacia 1789 se incorporó al taller del maestro Juan Debono "aprovechando fructuosamente su enseñanza por espacio de nueve años"; en 1799, fallecido Debono, consiguió el título de maestro organero de fábricas del arzobispado, pero el nombramiento no le fue revalidado; en 1804 pasa a ser afinador de los órganos de la catedral de Sevilla. Cfr. Antonio Ramírez Palacios, "Dinastías de organeros en Andalucía en los siglos XVIII y XIX", en Antonio Bonet Correa (ed.), El órgano español. Actas del II Congreso Español de Órgano. Madrid: Ministerio de Cultura-INAEM, 1987, 151161, en concreto, 154-155.

13 P. Cayetano Fernández Cabello, El Oratorio de San Felipe Neri de Sevilla. Su historia, instituciones, particularidades y biblioteca oratoriana. Sevilla: Izquierdo y compañía, 1894, 88-89. 
ofertorios y elevaciones ejecutadas en él por el antiguo organista, ya difunto, el presbítero D. José $\mathrm{M}^{\mathrm{a}}$ Valle.

Este órgano consiguió sobrevivir a la ocupación francesa de la ciudad (1810-12), e incluso a la exclaustración del oratorio sevillano en $1836,{ }^{14}$ pero no al bombardeo al que sometieron a la ciudad las tropas del general Van Halen en julio de 1843, pues cayeron dos bombas en el templo filipense, una de las cuales inutilizó el instrumento, el cual, al poco tiempo,"debió fabricarse de nuevo, o al menos recomponerse ${ }^{\prime 15}{ }^{15} \mathrm{El}$ instrumento renovado consiguió resistir a la momentánea supresión de la congregación filipense entre 1854 y 1856, pero ya no pudo con la revolución de septiembre de 1868, la Gloriosa, cuyos junteros sevillanos decretaron la expulsión de los congregantes, la incautación de sus bienes y, finalmente, el derribo de su iglesia y casa:"el Oratorio había sido destruido el 5 de octubre de 1868. Sus enseres fueron repartidos entre las siguientes instituciones: asilo de mendicidad de San Fernando de Sevilla, catedral, parroquia de Nuestra Señora de la O, parroquia del Salvador y museo provincial" ${ }^{16}$

Consta que entre el 6 de octubre y el 2 de noviembre de 1868, un juez de primera instancia de Sevilla supervisó personalmente "la formación de un inventario completo de cuanto se contenía en el Oratorio", documento que fue remitido al alcalde de la ciudad el 5 de noviembre: entre los bienes inventariados judicialmente figuraba, naturalmente, el órgano de la iglesia. ${ }^{17}$ Igualmente consta que el ayuntamiento sevillano, en sesión ordinaria celebrada el 7 de octubre de ese año ya autorizó a "la comisión que entiende en el derribo del convento de S. Felipe Neri" para otorgar a la iglesia de la $\mathrm{O}$, en Triana, tal como solicitaba el párroco Manuel Adalid de Requena,"las gradas, baldosas y efectos del primer edificio, que en su prudente juicio fuesen aplicables con provecho al segundo templo". ${ }^{18} \mathrm{En}$ el ar-

14 Según un inventario de la iglesia de San Felipe, fechado el 5 de mayo de 1836, "en las tribunas está el órgano y doce bancos y un escabelito para el organista"; Archivo General del Arzobispado de Sevilla (AGAS), Gobierno, Órdenes Religiosas Masculinas, legajo 21 (05268), expediente 1.

15 Martín Riego y Roda PeÑa, El Oratorio, 584-585. Las reparaciones de los daños sufridos por las bombas ascendieron a 40.000 reales y la iglesia permaneció cerrada al culto los tres meses que duraron las obras de reparación; ibídem, 211.

16 Martín Riego y Roda Peña, El Oratorio, 236.

17 Cf. Martín Riego y Roda Peña, El Oratorio, 450.

18 Ibídem, 453, n. 75. 
chivo municipal de Sevilla se conserva un inventario de los efectos trasladados a la iglesia de Nuestra Sra. de la O desde la de San Felipe, "firmado el 21 de octubre de 1868 por el párroco Manuel Adalid de Requena y el prioste de la cofradía Rafael de Lacambra"; ${ }^{19}$ por otra parte, en el archivo del arzobispado hispalense se conserva una nota, sin fecha, ${ }^{20 "}$ "del inventario de los enseres del culto y otros efectos que se han depositado en la iglesia de Ntra. Sra. de la O, pertenecientes a la de San Felipe".$^{21}$ En dicha nota, posiblemente sacada del inventario del 21 de octubre, se dice al final:"Existe en este templo [de la $\mathrm{O}$ ] una pequeña parte de la armadura del órgano", ${ }^{22}$ de donde se puede deducir que para entonces ya había comenzado a trasladarse el instrumento desde San Felipe.

Por un acta del cabildo de la hermandad de la O celebrado poco tiempo después, el 8 de noviembre de 1868, nos enteramos de importantes detalles; así en aquella reunión, el párroco de Santa Ana, Manuel Adalid, "a la sazón autoridad competente en la iglesia auxiliar de la $\mathrm{O}^{\prime}$, se dirigió a los cofrades diciéndoles que "por la influencia de algunos hermanos, en unión del prioste de la hermandad, recibimos del Excmo. Ayuntamiento constitucional de esta ciudad, bajo inventario y procedente del derribo de San Felipe Neri, las baldosas que pisamos, los altares (...), el órgano y otras cosas que todos han visto y han ayudado a traerlas". ${ }^{23}$ Adalid participó a los hermanos de la O que la autoridad eclesiástica le había reclamado el citado órgano "el cual destina a la Santa Iglesia Metropolitana", ofreciéndole a cambio "otro órgano de una de las iglesias suprimidas", para que los hermanos decidiesen qué hacer ante esta eventualidad, pues no quería determinar por sí solo en este asunto. A Adalid respondió el prioste Lacambra, diciendo que"en nombre de la hermandad y contando con la influencia y valimiento de uno de nuestros hermanos, que en la actualidad era alcalde constitucional" había recibido de la

\footnotetext{
19 Ibíd., 452, n. 74.

20 Algunos autores, fechan esta nota el 18 de octubre de 1868 y la hacen firmada por los mismos que firmaron el inventario anterior, pero, según Roda Peña, la nota sólo está rubricada por el párroco Adalid. Cfr. Pedro M. MarTínez Lara, “La hermandad de la O en los siglos XIX y XX", en VV. AA. Historia de la O. Una hermandad para un barrio. Sevilla: Hermandad de la O, 2007, 183-268, en concreto, 195 y Martín Riego y Roda Peña. El Oratorio..., 452, n. 74.

21 Martín Riego y Roda PeÑa, El Oratorio..., 452, n. 74. La cursiva es nuestra.

22 Ibídem, 452, n. 74.

23 Martínez Lara,“La hermandad”, 193.
} 
corporación municipal "los enseres que habían venido a la iglesia" y que firmó el inventario "creyendo obrar bien en el sentido de mejorar nuestra iglesia" y que si lo hizo sin consultar a la hermandad fue por la premura de tiempo, oponiéndose "resueltamente a devolver el órgano y mucho menos reclamándolo la autoridad eclesiástica, de quien ni nada había entregado ni intervenido en ello"; habiéndose sometido el asunto a votación, por unanimidad de los asistentes se aprobó la no entrega del órgano, nombrándose, a continuación, una comisión de hermanos "para que procure su colocación del modo más conveniente", lo que indica a las claras que el órgano aún no había sido instalado en su nueva ubicación. ${ }^{24}$

Una vez pasado el vendaval revolucionario, los filipenses sevillanos se volvieron a reunir en la ciudad para restablecer el oratorio; tan pronto como el 24 de enero de 1875 se reunieron los miembros de la congregación bajo la presidencia del padre decano al objeto de nombrar una comisión, compuesta por tres padres, que "gestionara todo lo conducente al reconocimiento legal del Oratorio y para que formase un inventario de los bienes conservados y de los que pudieran rescatarse" ${ }^{25}$ Un año después, el instituto religioso había sido reconocido por el gobierno de la nación, sus miembros habían reiniciado la vida en comunidad y la autoridad eclesiástica, en sede vacante por fallecimiento del arzobispo Lastra y Cuesta (1863-1876), les había concedido in verbis la iglesia de San Alberto de Sevilla (20 de mayo de 1876); el 6 de marzo de 1877 los filipenses eligieron como nuevo prepósito al padre Francisco García Tejero. Por un decreto del arzobispo Lluch y Garriga (1877-1882), de fecha 24 de noviembre de 1878 , se les entregaba oficialmente a los filipenses la iglesia que venían ocupando de facto, nombrándose capellán de la misma al prepósito de la congregación, P. Tejero. ${ }^{26}$ Luego de no pocas vicisitudes, el P. Tejero consiguió que el arzobispo de Sevilla dictase un decreto el 4 de febrero de 1878 del tenor siguiente: ${ }^{27}$

24 El acta de cabildo, de donde se toman las citas textuales, en MArTínez LarA, “La hermandad", 193-194. Este autor dice también que el citado órgano "se quería para la capilla real" de la seo hispalense.

25 Martín Riego y Roda Peña, El Oratorio, 241.

26 Ibídem, 243 y 247-248.

27 AGAS, Gobierno, Órdenes Religiosas Masculinas, legajo 21 (05268), expediente 1. La cursiva es nuestra. 
En vista de lo expuesto últimamente por el R. P. Prepósito de la Congregación del Oratorio de San Felipe Neri respecto a reclamar los objetos propios de la misma existentes en la parroquia auxiliar de $\mathrm{N}^{\mathrm{a}} \mathrm{S}^{\mathrm{a}}$ de la $\mathrm{O}$, en Triana, limitándose a pedir la devolución del órgano y 5 lámparas y que se le reconozca a la Congregación el derecho de propiedad que tiene a los demás objetos, que su consideración a las razones que aquel cura alega, las deja ahora para el uso de dicha parroquia auxiliar; ordenamos y mandamos al expresado Cura haga entrega, con las formalidades debidas, al R. P. Prepósito del órgano y de las cinco lámparas que quedan referidas; dándonos cuenta de haberlo así verificado y remitiéndonos a la vez una Nota autorizada con su firma de todos los objetos, útiles y enseres que allí existen y que reconozca sean de la propiedad de la Congregación del Oratorio de S. Felipe Neri.

El nuevo párroco de Santa Ana y encargado de la iglesia de la O, Francisco Gil, cumpliendo lo mandado en el anterior decreto, remitió al arzobispado sendos oficios, fechados respectivamente el 8 y el 16 de febrero; en el primero de ellos daba cuenta a la autoridad eclesiástica de lo acontecido con el órgano: ${ }^{28}$

En la tarde del 6 del corriente recibí la orden queV. S. se sirvió remitirme para que entregase al P. Prepósito (...) el órgano de esta iglesia de la $\mathrm{O}$ y cinco lámparas. El día 7 se me presentó el referido P. Prepósito, acompañado de otro padre, y convinimos en la entrega de dichos objetos para hoy, a las 10 de la mañana. Efectivamente, después de las 11 ha venido un maestro organero a desmontar y llevarse el órgano; pero habiéndose presentado muchos hermanos de $\mathrm{N}^{a} \mathrm{~S}^{\mathrm{a}}$ de la $\mathrm{O}$, han impedido la entrega, alegando que ellos son los únicos propietarios de esta iglesia y de todo lo contenido en ella. No ha habido desorden ni palabras descompuestas. Lo que me apresuro a ponerlo en conocimiento deV.S. para que me dé sus órdenes superiores.

En el oficio del día 16, el cura de la O acompañaba un"inventario de los objetos que en dicha auxiliar se conservan pertenecientes a la iglesia de San Felipe de esta ciudad", entre los cuales figuraba el órgano; este inventario lleva fecha de 12 de febrero de 1878.

El oratoriano Cayetano Fernández nos dejó una última noticia, a finales del siglo XIX, acerca del órgano de San Felipe de Sevilla:"se encuentra montado y en uso en la iglesia de la O de Triana, habiendo sido infructuosos todos los esfuerzos imaginables para arrancarlo de las robustas manos de la Hermandad de Nuestro P. Jesús Nazareno y

28 Ibídem. La cursiva es nuestra. 
María Stma. de la $\mathrm{O}^{\prime \prime} .{ }^{29} \mathrm{Y}$ en la iglesia de la O continuó el instrumento hasta el presente, donde parece que sufrió algunos desperfectos durante el saqueo de dicho templo en julio de 1936, siendo reparado en las primeras décadas del siglo pasado por Domingo Florenzano; en nuestros días, según los historiadores de la hermandad, el órgano "muy deteriorado e inservible, espera una restauración". ${ }^{30}$

\section{EL ÓRGANO DE LA IGLESIA DE SAN ALBERTO}

$\mathrm{Si}$, como acabamos de ver, del órgano de la iglesia de San Felipe se conoce bastante bien su historia, no sucede lo mismo con el que ahora nos ocupa, acerca del cual no es mucho lo que se sabe; debemos comenzar diciendo que resulta llamativo que Ayarra no lo trate en una de sus obras de referencia, la publicada en 1978, cuando nos consta que por aquellas fechas el instrumento, al menos su caja, aún estaba montado y visible en el coro de la iglesia de San Alberto; en cambio, sí lo cita, aunque de pasada, en el inventario publicado en 1998, como uno de los instrumentos ruinosos; ${ }^{31}$ tampoco tratan de este instrumento Martín Riego y Roda Peña en su excelente monografía sobre la historia y el patrimonio del oratorio sevillano.

Una de las primeras gestiones realizadas por los filipenses sevillanos con vistas a su reinstauración en la ciudad fue la búsqueda de un templo en el cual poder realizar sus ministerios, una vez desaparecida para siempre la iglesia de San Felipe; el 13 de marzo de 1875, dirigieron una súplica al arzobispo de Sevilla, Lastra y Cuesta, con este motivo; el prelado les contestó el 8 de abril siguiente señalándoles la iglesia de Nuestra Señora del Buen Suceso, que había pertenecido al hospital de los obregones, "para que puedan provisionalmente establecer en ella sus santos ejercicios y demás actos

29 Fernández Cabello, El Oratorio..., 113. La cursiva es nuestra.

30 Para estas noticias, cfr. Ayarra, El órgano..., 141; Martín Riego y Roda PeÑa, El Oratorio, 585 y MARTínEz LARA, “La hermandad”, 197. Una detallada descripción del estado actual del órgano puede verse en José Enrique AYARRA JARNé, Órganos en la provincia de Sevilla. Inventario y catálogo. Granada: Junta de AndalucíaConsejería de Cultura, 1998, 265-267.

31 Cf. AyARra Jarné, Órganos, 44. Allí dice este autor:"A esa lista ya interminable de instrumentos ruinosos, podríamos añadir todavía algunos más, de los que nos quedan tan sólo restos inaprovechables [sic], como - por ejemplo- el de la iglesia de S. Alberto de Sevilla (PP. Filipenses) (...) construido con toda probabilidad en las postrimerías del siglo XVIII...". 
religiosos de su sagrado instituto", pero en 23 del mismo mes, los oratorianos declinaron el ofrecimiento realizado por el arzobispo alegando, entre otras cosas, que dicha iglesia carecía de "presbiterio y órgano", y señalando como más apropiado el templo sevillano de San Alberto, cuyo uso les fue concedido in verbis por la autoridad diocesana, como ya vimos. ${ }^{32}$

La historia del colegio carmelitano de San Alberto de Sevilla y de su patrimonio artístico resulta bastante bien conocida, por lo que no vamos a entrar en ella; ${ }^{33}$ tan sólo diremos que la exclaustración general de los frailes decretada por la junta revolucionaria de Sevilla supuso el cierre definitivo de este convento, permaneciendo su iglesia en 1835 abierta al culto y regentada por capellanes ex carmelitas hasta el año 1868, en que el arzobispo de Sevilla, Lastra y Cuesta, nombró como capellán de dicha iglesia a un ex religioso agustino calzado, quien ejercería como tal hasta su fallecimiento en 1877; como ya hemos dicho, los filipenses ejercían sus ministerios en este iglesia desde 1876.

Sobre la historia del órgano de la iglesia de San Alberto es muy poco lo que sabemos; se puede conjeturar que se ejecutara durante el provincialato del P. Francisco Muñoz († 1782), entre los años 1770 y 1775, de quien consta que "hizo de su peculio la hermosa sillería de coro y facistol de dicho colegio de San Alberto de Sevilla", don-

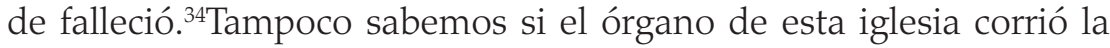
misma suerte que su retablo mayor que, según parece, fue destruido durante la ocupación francesa de la ciudad, entre 1810 y 1812, periodo durante el cual la iglesia fue expoliada "padeciendo numerosos destrozos el patrimonio artístico del templo que fue, en buena medida, reparado por los carmelitas a su regreso, siendo nuevamente consagrada la iglesia el 16 de mayo de $1815^{\prime \prime} .^{35}$

El 2 de septiembre de 1835 los carmelitas de San Alberto fueron obligados a abandonar su convento, quedando la iglesia abierta al

32 Cfr. Martín Riego y Roda Peña, El Oratorio, 244-246.

33 Remitimos para ello a los trabajos de Ismael MarTínez CARRetero, Los carmelitas en Sevilla. 650 años de presencia (1358-2008). Sevilla: Provincia Bética Carmelitana, 2009, y de Matilde Fernández Rojas, Patrimonio artístico de los conventos masculinos desamortizados en Sevilla durante el siglo XIX. Sevilla: Diputación Provincial, 2008, 432-468. Por cierto, tampoco estos autores tratan del órgano de su iglesia.

34 Fr. Miguel Rodríguez CARretero, o carm. Epítome historial de los carmelitas de Andalucía y Murcia. Ms. Edición: Sevilla, 2000, 424.

35 Fernández Rojas, Patrimonio, 437. 
culto pero bajo la jurisdicción diocesana. Por un curioso inventario de la iglesia, que se conserva en el archivo del arzobispado hispalense, ${ }^{36}$ podemos hacernos una idea bastante exacta de cuál era el estado de la misma poco después de que les fuera despojada para siempre a los religiosos carmelitas; este inventario, fechado el 24 de septiembre de 1835, fue realizado con ocasión de la entrega de dicha iglesia para su custodia al cura de la parroquia de San Isidoro, a cuya collación pertenecía el templo conventual, "por Decreto del Intendente de esta Provincia, su fecha veinte y uno de septiembre, refiriéndose a la disposición de la Junta Directiva de la misma de diecisiete del mismo mes", es decir, de la junta revolucionaria que se había hecho con el poder en la ciudad y provincia de Sevilla desde los primeros días de septiembre. ${ }^{37}$ En este inventario se cita como existente en dicha iglesia un órgano, que se enumera entre los objetos de la nave del templo, por estar colocado en la primera tribuna del lado del evangelio, junto al coro y no en el propio coro, donde sólo se citan:"un facistol de madera; dos campanilleros de hierro con cuatro campanillas; cinco bancos; diez y nueve óvalos de madera, en que se hallan pintadas diferentes imágenes, cuyos óvalos fueron respaldo de los asientos del antiguo coro". 38

Al hacerse cargo los filipenses de la iglesia de San Alberto se redactó un inventario de los bienes que en aquel momento existían en el templo; el inventario lleva fecha de 1 de junio de 1878 y en él también se incluía, entre los "objetos varios", el órgano y"un facistol sin segundo cuerpo".${ }^{39} \mathrm{Habría}$ de suponerse que este órgano era el mismo que existía al tiempo de la exclaustración de los carmelitas, pero esto no tiene por qué ser así, pues consta que entre el 10 de diciembre de 1877 y el 3 de marzo de 1878 los oratorianos llevaron a cabo unas importantes obras en la iglesia de San Alberto que no se limitaron"a la fábrica del templo propiamente dicha (...), sino que se

36 Cf. AGAS. Gobierno, Órdenes Religiosas Masculinas, legajo 21, expediente 1: Sevilla. San Alberto. Inventario de los objetos del culto, vasos sagrados, ornamentos y demás efectos del culto pertenecientes a la Iglesia de dicho suprimido convento.

37 Esta junta ejerció un poder soberano en Sevilla y su distrito desde el 2 de septiembre al 5 de octubre de 1835; cfr. José VelázQueZ y SÁncheZ, Anales de Sevilla de 1800 a 1850. Sevilla, 1872, edición facsímil en Sevilla: Ayuntamiento, 1994, 440-443.

38 AGAS. Gobierno, Órdenes Religiosas Masculinas, legajo 21, expediente 1.

39 Ibídem. 
extendió a los altares, verjas de las capillas, órgano y otros elementos de ornato" ${ }^{40}$ si la intervención en el órgano se limitó a su restauración o fue una sustitución por otro, es algo que no nos consta. ${ }^{41}$

Las siguientes noticias corresponden ya al siglo XX; así, en el archivo del oratorio sevillano se conserva un expediente relativo al traslado y reparación del órgano de esta iglesia en 1943, el cual estaba inservible desde al menos veinte años antes. ${ }^{42}$

De la lectura de la documentación que obra en el citado expediente, podemos concluir que en diciembre de 1942 un organero de apellido Jiménez, a solicitud de la congregación, presentó a los oratorianos de Sevilla un presupuesto para "la reparación y el traslado del órgano de la iglesia de San Alberto"; según el desglose de dicho presupuesto, los trabajos a realizar comprendían desmontar el órgano de su ubicación, en una de las tribunas del lado del evangelio, y trasladarlo al centro del coro, reparación de los fuelles y posterior montaje y afinación del instrumento; además el presupuesto incluía las siguiente innovaciones a realizar en el órgano:

- Inversión del teclado "teniendo en cuenta que para hacer esta innovación hay que cambiar por completo el sistema de tiraje de las válvulas, con objeto de que el organista no quede de espaldas al altar".

- Inversión del tiraje de los registros.

- "Construcción de una reducción de poleas para la propulsión de los fuelles por un motor eléctrico".

Estas innovaciones se ilustraban mediante un dibujo, adjunto al presupuesto, que reproducimos en la página siguiente. Los trabajos fueron presupuestados por el maestro en 2.870 pesetas, sin incluir el motor eléctrico ni los trabajos de carpintería necesarios para el traslado del órgano, que se facturarían aparte; incluyendo estas dos rúbricas, el maestro estimaba que el coste total de la operación podía ascender a unas 3.900 pesetas.

\footnotetext{
40 Martín Riego y Roda Peña, El Oratorio, 605.

${ }^{41}$ Sí nos consta, en cambio, que en aquellos años el trasiego de órganos entre templos de la diócesis fue bastante importante.

42 Archivo General de la Congregación del Oratorio de San Felipe Neri de Sevilla (AGCOSFNS), Archivo Administrativo, legajo 19, expediente 6. A él se referirán todas las citas textuales a partir de ahora, por lo que omitimos la innecesaria reiteración de notas a pie.
} 


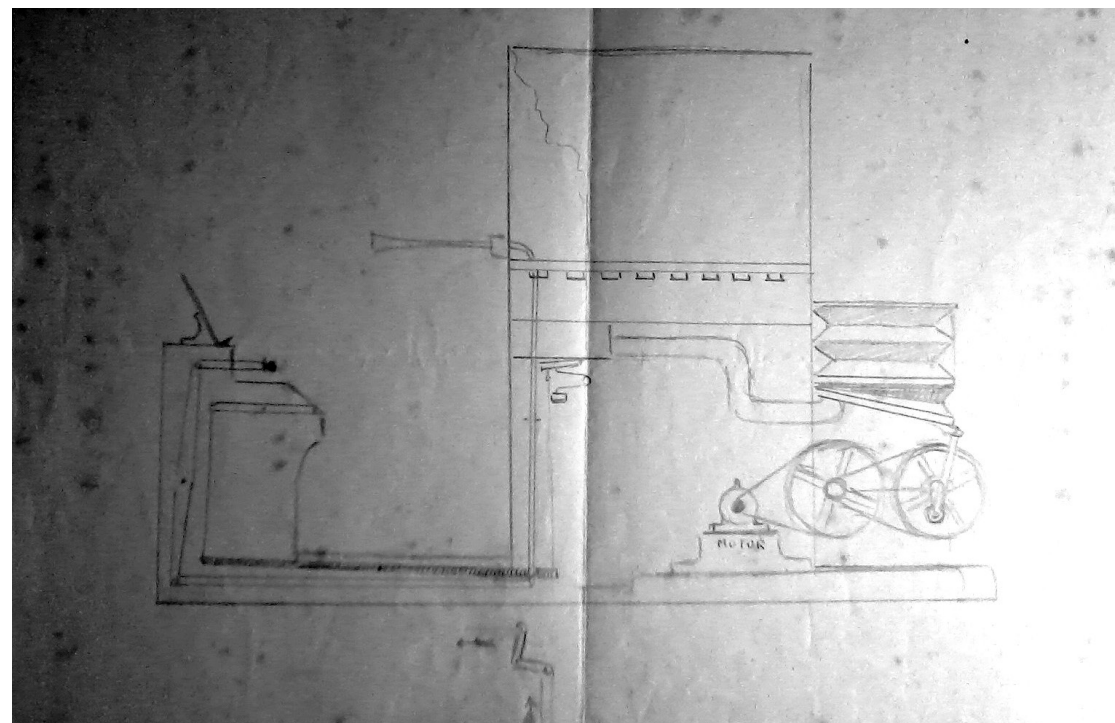

Croquis de la reparación del órgano de San Alberto en 1943 (Archivo Congregación del Oratorio de Sevilla)

Este presupuesto debió ser aceptado por la comunidad filipense, pues consta que en reunión celebrada el 24 de enero de 1943, los dos únicos padres que formaban la comunidad por entonces acordaron por unanimidad "manifestar su satisfacción por la inauguración del nuevo órgano, que hacía veinte años se hallaba parado, inservible, en la primera tribuna, junto al coro, del lado del Evangelio. Desmontado y trasladado, había sido colocado en medio del coro, con la consola nueva y ventilación eléctrica"; ${ }^{43}$ según ese mismo acta, el órgano fue estrenado aquel día"mereciendo la congregación felicitaciones de los fieles, llenos de entusiasmo y gratamente impresionados al oír, después de tantos años el órgano, que podía llamarse nuevo, en nuestra iglesia" ${ }^{44}$ Pocos días después, el 5 de febrero de aquel año, el organero Jiménez presentó al cobro a la congregación la factura con el importe total de sus honorarios por los trabajos realizados que ascendió a un total de 3.000 pesetas, pues además de lo presupuestado, incluía 130 pesetas por el arreglo del armonio de la iglesia.

\footnotetext{
43 AGCOSFNS, Archivo Histórico, legajo 16, libro $3^{\circ}$ de acuerdos, nº 120.

44 Ibídem.
} 
El órgano de San Alberto en su última ubicación (Archivo Congregación del Oratorio de Sevilla)

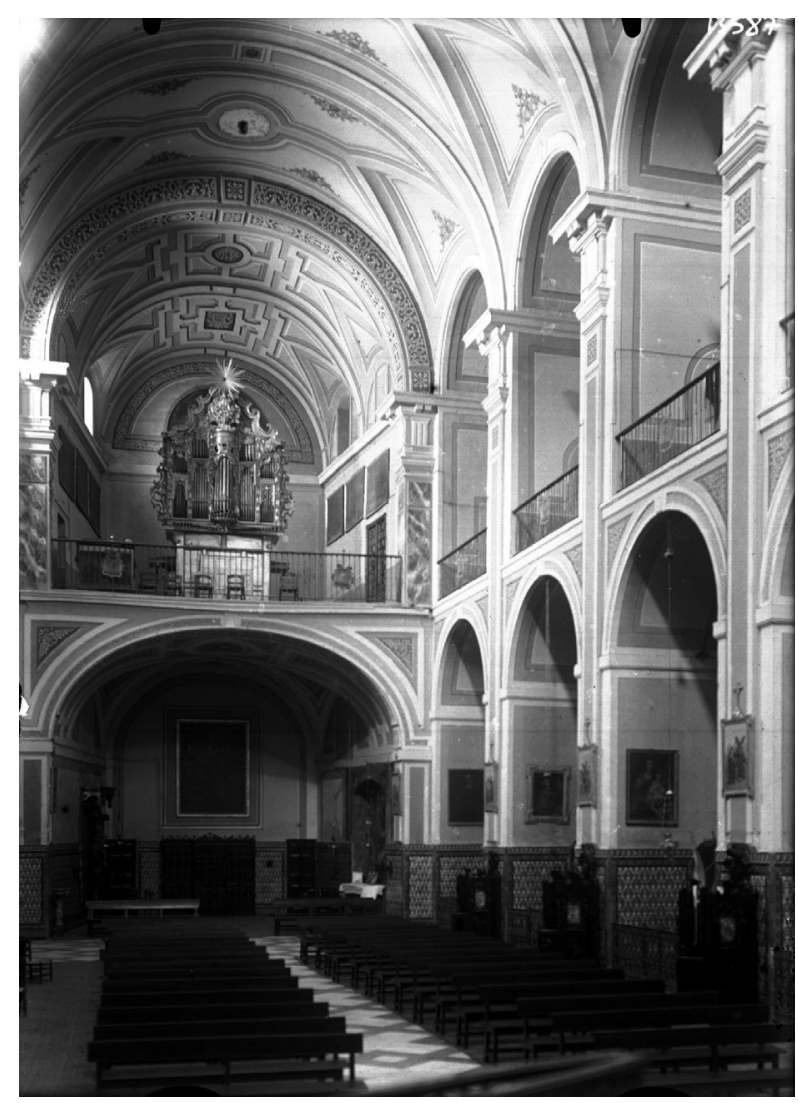

Las últimas noticias que tenemos sobre el órgano de que estamos tratando son referidas al año 1994; por entonces, la diputación provincial de Sevilla había puesto en marcha una escuela-taller para la reparación y reconstrucción de los órganos de la provincia que se llamó "Jorge Bosch". Uno de los instrumentos que iban a ser restaurados por esta escuela-taller era precisamente el de la iglesia de San Alberto; en el archivo de la congregación se conserva aún una copia de la autorización que dio el entonces prepósito de los filipenses para proceder a la restauración del órgano. En ese documento, el instrumento era descrito de la siguiente manera:"Órgano barroco del siglo XVIII compuesto por siete juegos y medio en su teclado manual de 49 
notas; se encuentra en lamentable estado debido a un accidente" ${ }^{45} \mathrm{Y}$ aunque todos se las prometían muy felices, pronto la polémica estalló en los medios de comunicación locales respecto a las dudas acerca de la supuesta capacitación de los miembros de la escuela-taller para acometer la restauración de los órganos sevillanos, y el arzobispado hispalense decidió vetar"por decreto"la intervención de la citada escuela-taller en los órganos bajo su jurisdicción. ${ }^{46}$ Se perdió así la única ocasión de recuperar este instrumento para la música, como decía el prepósito en su escrito y, poco tiempo después, se decidió retirar del coro los últimos restos del mueble, que permanecen guardados a la espera de tiempos mejores.

45 AGCOSFNS, Archivo Administrativo, legajo 19, expediente 6. No se indica ni la causa del accidente ni la fecha del mismo.

46 Así en ABC de Sevilla de 23 de julio de 1996, p. 69, en crónica firmada por Jesús Álvarez. 